\title{
Forecasting residential electricity demand in provincial China
}

\author{
Hua Liao ${ }^{1,2,3}$ - Yanan Liu ${ }^{1,2,3}$-Yixuan Gao ${ }^{1,2,3,4} \cdot$ Yu Hao ${ }^{1,2,3} \cdot$ Xiao-Wei Ma ${ }^{1,2,3}$. \\ Kan Wang ${ }^{1,2,3}$
}

Received: 7 August 2016/Accepted: 13 December 2016/Published online: 30 December 2016

(C) Springer-Verlag Berlin Heidelberg 2016

\begin{abstract}
In China, more than $80 \%$ electricity comes from coal which dominates the $\mathrm{CO} 2$ emissions. Residential electricity demand forecasting plays a significant role in electricity infrastructure planning and energy policy designing, but it is challenging to make an accurate forecast for developing countries. This paper forecasts the provincial residential electricity consumption of China in the 13th Five-Year-Plan (20162020) period using panel data. To overcome the limitations of widely used predication models with unreliably prior knowledge on function forms, a robust piecewise linear model in reduced form is utilized to capture the non-deterministic relationship between income and residential electricity consumption. The forecast results suggest that the growth rates of developed provinces will slow down, while the less developed will be still in fast growing. The national residential electricity demand will increase at $6.6 \%$ annually during 2016-2020, and populous provinces such as Guangdong will be the main contributors to the increments.
\end{abstract}

Responsible editor: Philippe Garrigues

Hua Liao

hliao@bit.edu.cn; liaohua5@gmail.com; liaohua55@163.com; https://ideas.repec.org/d/cebitcn.html; http://www.ceep.net.cn/ english/index.htm

1 Present address: School of Management and Economics, Beijing Institute of Technology, 5 Zhongguancun South Street, Haidian District, Beijing 100081, China

2 Center for Energy and Environmental Policy Research (CEEP), Beijing Institute of Technology (BIT), Beijing 100081, China

3 Collaborative Innovation Center of Electric Vehicles in Beijing, Beijing 100081, China

4 University of New Hampshire, 56 College Rd, Durham, NH 03824, USA
Keywords Electricity demand · Forecast · Piecewise linear model $\cdot$ China $\cdot$ Residential sector $\cdot$ Provincial panel data

\section{Introduction}

In China, more than $80 \%$ electricity comes from coal which dominates the $\mathrm{CO}_{2}$ emissions. During the past two decades, China has been experiencing a soaring increase in residential electricity consumption. In the next decades, residential sector will play an increasing role in $\mathrm{CO}_{2}$ emission mitigation. The residential electricity consumption climbed drastically to 727.6 TWh in 2015, which is seven times more than that in 1995. However, the per capita amount is still much lower compared with developed countries. As shown in Fig. 1, in average, each Chinese resident consumes $513 \mathrm{kWh}$ electricity in 2013, below the world average level $(740 \mathrm{kWh})$. As a comparison, the levels of per capita residential electricity consumption of the USA, France, and Japan were 4395, 2547, and $2295 \mathrm{kWh}$, respectively. These data are eight times, five times, and four times more than the levels of China, in sequence. In addition, the residential electricity consumption constitutes more than $30 \%$ of household energy used in developed countries, but it only accounts for $15 \%$ in China. Residential electricity consumption and its proportion to household energy consumption are important indicators of living standards. In the 13th Five-Year-Plan period (20162020), China vows to complete building a well-off society in an all-round way and achieve a series of ambitious targets regarding environment and cleaner energy. Given the continuous improvement of living standards and energy consumption structure adjustment, residential sector will become the main engine of Chinese electricity consumption growth in the foreseeable future. To meet the future demand of electricity 
Fig. 1 Residential electricity consumption per capita in 2013 and its share by final electricity consumption. Data source: IEA

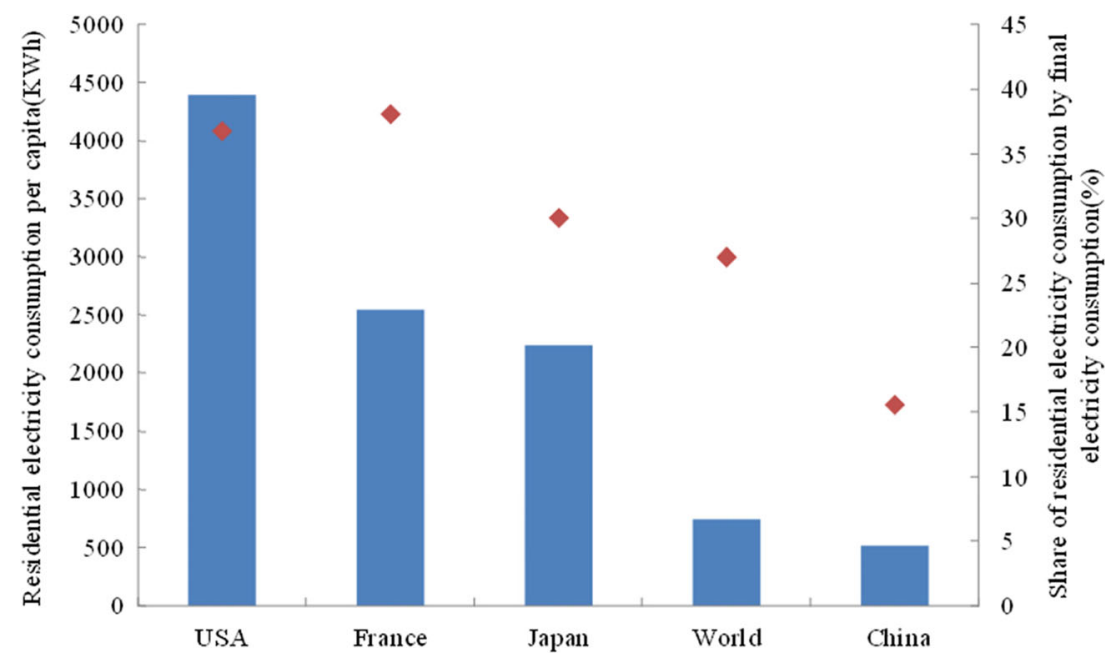

demand in resident sector, an accurate forecast is desirably needed.

Electricity demand forecasting plays a significant role in electricity system planning, energy policy designing, and social stabilization (Dergiades and Tsoulfidis 2008; Son and Kim 2016). Underestimation would result in insufficient generation and unmet demand. By contrast, overestimation may lead to substantial waste of energy, given the fact that electricity cannot be stored on a large scale using existing technologies, and that plant expansion required huge amount of capital investment and long construction period (Sadeghi Keyno et al. 2009; Son and Kim 2016).

There are many uncertainties in the future (Schweizer and Morgan 2016). As is well known, it is a great challenge to forecast electricity demand, especially for the developing countries and long-term prediction. Compared with developed countries, where economic and power systems are mature and stable, developing countries are in the process of fast growing with unstable social and economic conditions, unexpected events, and technology breakthrough. All of these uncertainties add difficulties to conducting an accurate electricity demand forecast (Lin 2003).

As the largest developing country and electricity consumer in the world, China has drawn increasing attentions home and abroad in terms of electricity consumption. There has been a growing body of literature on the forecast of Chinese electricity consumption (Adams and Shachmurove 2008; von Hirschhausen and Andres 2000; Steenhof and Fulton 2007). However, the earlier forecasts underestimated China's electricity consumption. As Liao et al. (2016) pointed out, underestimation of investment in China's electricity market leads to a nationwide electricity shortage in 2002 and lasts in the following years. During the worst time of 2004, 26 of China's 34 provinces were plagued by the shortfalls, which had a severe impact on resident's daily life and industrial output.
Generally speaking, the limitations of empirical methods should be noted for the unreliable forecasts. So far, the empirical methods widely used in electricity consumption forecast include neural network, time-series analysis, and multivariate analysis. Neural network method sometimes has good forecast performance based on historical data, but its mechanism is like a black box with unexplained mathematic models (Darbellay and Slama 2000). Furthermore, neural network analysis requires a large data sample. In contrast, time-series analysis, such as the autoregressive and integrated moving average model (ARIMA), has become popular in electricity demand forecasting (Pappas et al. 2008). However, the time-series analysis usually only depends on historical data to forecast with a somewhat arbitrage assumption that past pattern will definitely persist in the future. It is suitable for short-term predictions. Among these methods, multivariate analysis enjoys a great popularity with the advantages of simplicity and low data requirement. The procedure of multivariate analysis is as follows: first, the relationship between independent and dependent variables is examined based on one specific model, and then the estimated regression model is employed to produce forecasts. Most often, the existing empirical studies specified a linear, squared double-logarithmic form or logistical model that imposes an ex ante restriction on the relationship between electricity consumption and the dependent variables (Mohamed and Bodger 2005). However, electricity consumption is influenced by many non-deterministic variables, including weather conditions, economics, and demographics (Son and Kim 2016). Besides, the existing literature explores time-series variation at the county level instead of province level, which would lose much information and reduce the accuracy of forecasting.

Based on these considerations, a piecewise linear model in reduced form that can capture the non-deterministic relationship and a province-level panel data set for 30 Chinese 
(a) GDP per capita

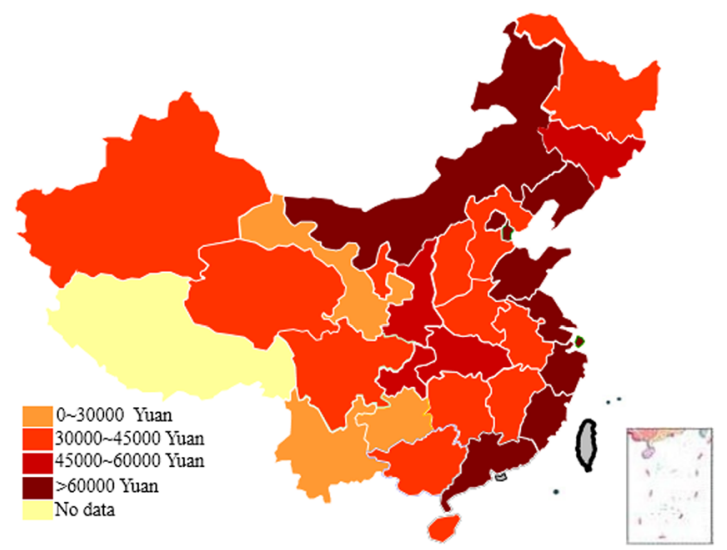

Fig. 2 Provincial GDP and residential electricity consumption at per capita level in 2014. a GDP per capita. b Residential electricity consumption per capita. Data sources: China Statistical Yearbook 2015

provinces and municipalities during 1995-2014 is adopted to forecast the provincial and national residential electricity demand in the 13th Five-Year-Plan period (2016-2020). Furthermore, the increment of electricity consumption is calculated, so that the specific provinces which are the main contributors to the increment could be figured out.

We contribute to literature in three aspects. First, to the best of our knowledge, this is the first paper forecasting the residential electricity demand in China. As the major contributor of future electricity consumption, residential sector deserves more attention. In this regard, our paper fills up the gap in this field and sheds some light on the possible energy policies at regional and national levels.

Second, instead of specifying a fixed model beforehand, a piecewise linear model in reduced form is utilized. Superior to the regression models in previous work, piecewise linear model can capture the non-linear relationship between income and residential electricity consumption and therefore is selfadaptive and flexible. Furthermore, both province fixed effect and time fixed effects are included into the piecewise model to control for the unobservable yet important influencing factors.

Third, compared with the previous studies using aggregate country level data, the heterogeneity across provinces is taken into full consideration with provincial panel data. Encompassing more than 30 provinces and municipalities, (b) Residential electricity consumption per capita

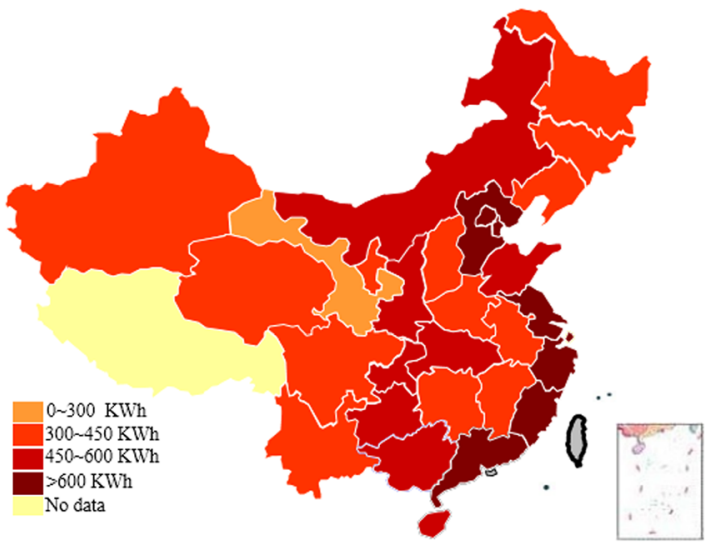

and Chinese Energy Statistical Yearbook 2015. It is a schematic map and does not implicate the definite boundaries

China is a vast country in territory. Different regions have significant differences in economic development and electricity consumption. These imbalances are depicted intuitionally in Fig. 2, which depicts GDP per capita and residential electricity consumption per capita in 2014. By 2014, the levels of GDP per capita in nine municipalities and provinces, including Beijing, Shanghai, Tianjin, Jiangsu, and Zhejiang, have surpassed $\$ 20,000$ (based on purchasing power parity), approaching the level of some advanced economies. It should be noted that the economically developed municipalities and provinces are mainly located in eastern coastal regions. However, in some remote western provinces, such as Gansu, Yunnan, and Guizhou, the level of GDP per capita is still considerably low. The significant gap in economic development across regions also affects the differences in residential electricity consumptions. For instance, the residents in coastal-developed provinces consumed a considerably higher level of electricity than their counterparts in western provinces. Therefore, to make a more precise and reliable forecast of residential electricity demand, it is necessary to take the heterogeneity across provinces into consideration.

The rest of this paper is organized as follows. The "The methodology and data" section presents the methodology and the data used in empirical analysis. The "Estimation results" section presents the empirical estimate results and brief

Table 1 Descriptive statistics

\begin{tabular}{|c|c|c|c|c|c|c|}
\hline Variable & Definition & Obs. & Mean & Std. Dev. & Min & Max \\
\hline$e$ & $\begin{array}{l}\text { Residential electricity consumption } \\
\text { (TWh) }\end{array}$ & 598 & 10.92 & 11.13 & 0.21 & 81.08 \\
\hline$y$ & GDP (million Yuan) & 598 & 99.67 & 106.80 & 3.01 & 678.10 \\
\hline pop & Population (M) & 598 & 42.98 & 26.22 & 4.81 & 114.30 \\
\hline epc & $\begin{array}{l}\text { Residential electricity consumption } \\
\text { per capita }(\mathrm{kWh})\end{array}$ & 598 & 251.19 & 173.27 & 29.56 & 906.54 \\
\hline ypc & GDP per capita (Yuan) & 598 & $23,961.60$ & $18,962.53$ & 3256.93 & $103,671.30$ \\
\hline
\end{tabular}


Table 2 Estimation results

\begin{tabular}{lll}
\hline $\ln \left(\mathrm{epc}_{\mathrm{it}}\right)$ & $(1)$ & $(2)$ \\
\hline Income spline1: 0-9876 & $0.197^{* * *}$ & $0.212^{* * *}$ \\
& $(0.070)$ & $(0.072)$ \\
Income spline: $9876-17,625$ & $0.157^{* *}$ & $0.208^{* * *}$ \\
& $(0.068)$ & $(0.065)$ \\
Income spline: $17,625-32,378$ & $0.114 * *$ & $0.135^{* * *}$ \\
& $(0.058)$ & $(0.055)$ \\
Income spline: $32,378-103,671$ & 0.015 & 0.041 \\
& $(0.071)$ & $(0.068)$ \\
$\ln ($ epc & $\left.0.730^{*}-1\right)$ & $0.724 * * *$ \\
& $(0.030)$ & $(0.030)$ \\
Year & - & $0.012 * *$ \\
& - & $(0.006)$ \\
Constant & - & $-23.641 * *$ \\
& - & $(11.209)$ \\
Time fixed effect & Yes & No \\
Province fixed effect & Yes & Yes \\
Obs. & 598 & 598 \\
\end{tabular}

The GDP per capita here is at 2014 constant price

**Statistical significance at $5 \%$

$* * *$ Statistical significance at $1 \%$

discussions. The "Forecasting technique and results" section reports the forecast results at both provincial and national levels. In the "Conclusions and policy implications" section, the main findings of this study are concluded, and the corresponding policy implications are given.

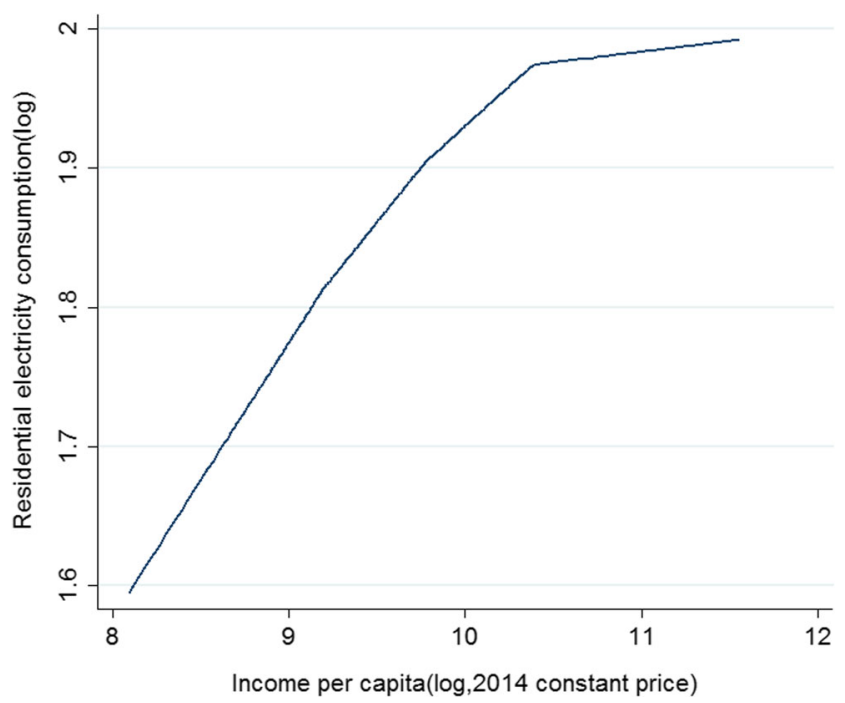

Fig. 3 Estimated income effect on residential electricity consumption. Note: The income range has been divided into 4 segments by percentile so each segment contains the same number of observations. The natural logarithms of the three per capita GDP breakpoints are 9.20, 9.78, and 10.39 , respectively. Residential electricity consumption per capita on the vertical axis has been adjusted for only the effect of income excluding the province fixed effect and year fixed effect

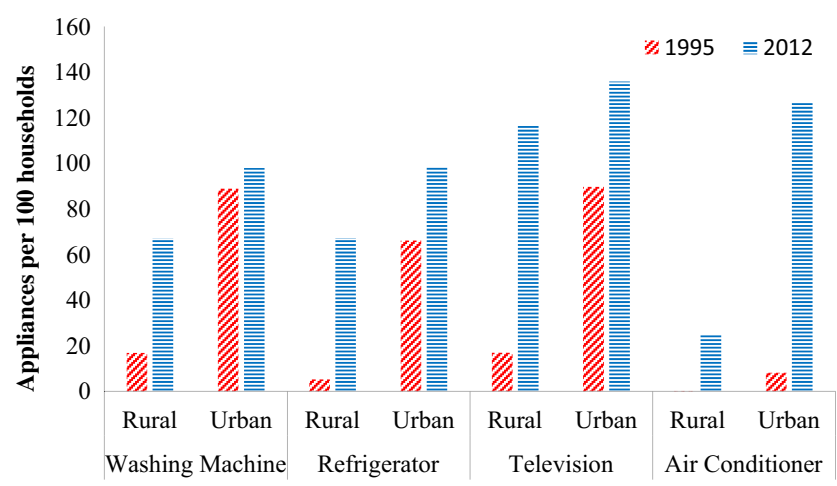

Fig. 4 The ownership of appliances per 100 households in China's rural and urban area. Data sources: China Statistical Yearbook 1996 and China Statistical Yearbook 2013

\section{The methodology and data}

\section{Model}

Income is regarded as the most important determinant of residential electricity consumption (Dikaios Tserkezos 1992; Hondroyiannis 2004). While the relationship between residential electricity consumption and income is non-deterministic at different levels of income. The electricity elasticity of income varies in time and across regions. Yoo and Lee (2010) detected an inverted U-shaped relationship between them in OECD and developed countries. At low income levels, a positive relationship will be shown since residents will allocate more budget on appliance purchase and use these appliances to increase income. When income reaches a certain threshold that enables households to possess enough energy-efficient appliances, the electricity consumption will be stable or decline.

To quantitatively capture the non-deterministic relationship between income and residential electricity consumption, we employ a piecewise linear model. The basic idea behind piecewise linear model is that if the data follow different linear trends over different ranges, then the regression function should be modeled in "pieces." Its graph consists of two or more straight line segments with a certain number of

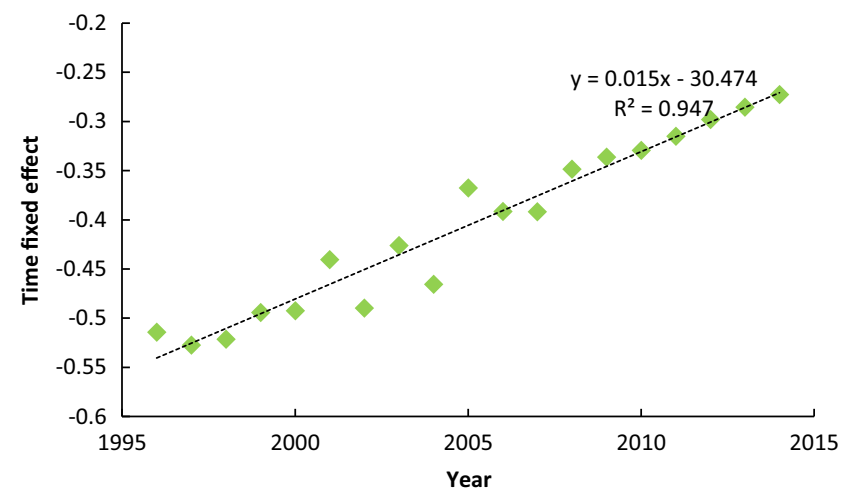

Fig. 5 Time fixed effect 
breakpoints. At the point of the structural break, the slope changes, but the lines remain continuous. Therefore, the model has the advantage of allowing the curve to present a much wider range of shapes rather than being only linear,

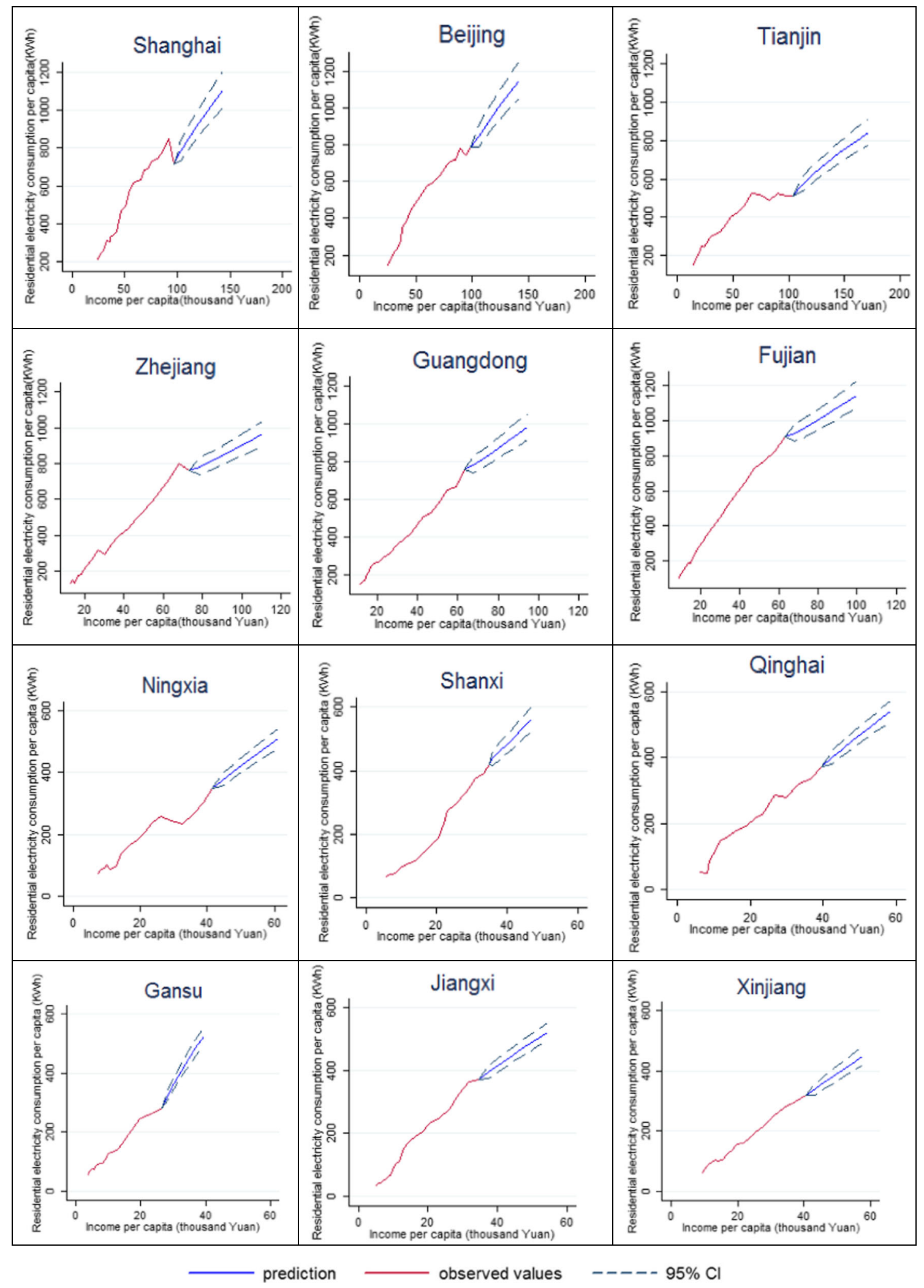

Fig. 6 Residential electricity consumption and income per capita for selected provinces in 1995-2020 
quadratic, or cubic (Liao and Cao 2013). Auffhammer and Carson (2008), Auffhammer and Steinhauser (2012), Liao and Cao (2013), and Schmalensee et al. (1998) used it to examine the non-linear relationship between $\mathrm{CO}_{2}$ emission and economic development.

In a reduced form, the model can be presented as follows: $\ln E_{\mathrm{it}}=\alpha_{0}+\alpha_{\mathrm{i}}+\mu_{\mathrm{t}}+\rho \ln \left(E_{\mathrm{it}-1}\right)+\beta_{\mathrm{k}} f\left[\ln \left(Y_{\mathrm{it}}\right)\right]+\varepsilon_{\mathrm{it}}$

where $E_{\mathrm{it}}$ is the per capita residential electricity consumption for province $i$ in year $t, Y_{\mathrm{it}}$ is the per capita income for province $i$ in year $t ; a_{\mathrm{i}}$ is the year fixed effect to control for the unobserved heterogeneity which changes with year but are the same to all the provinces, such as national energy policy and frontier technological progress; $\mu_{\mathrm{t}}$ is the year fixed effect to control for unobserved province-invariant heterogeneity, such as national energy policy and frontier technological progress; $\alpha_{0}$ is a constant; $\varepsilon_{\mathrm{it}}$ is the error term; $k$ represents the number of segments; and $f(\cdot)$ is the piecewise linear function based on the number of segments. According to the nature of the double logarithm model, the coefficient $\beta$ represents the income elasticity. In order to capture the impact of previous electricity consumption, 1-year lagged residential electricity consumption is included in the specification.

In addition to income, residential electricity consumption can be influenced by a variety of factors, such as electricity price, alternative energy price, urbanization rate, electricity access rate, and heating degree days (Alberini et al. 2011; Blázquez et al. 2013; Dergiades and Tsoulfidis 2008; Holtedahl and Joutz 2004; Musango 2014). Similar to Schmalensee et al. (1998), we include only per capita income in the reduced function, leaving the other explanatory variables uncontrolled for the following reasons. First, the data of electricity prices and alternative energy prices for the full sample are not available. In addition, there is little variation in price across years and provinces. Second, many factors (e.g., weather conditions, geographic position, technological

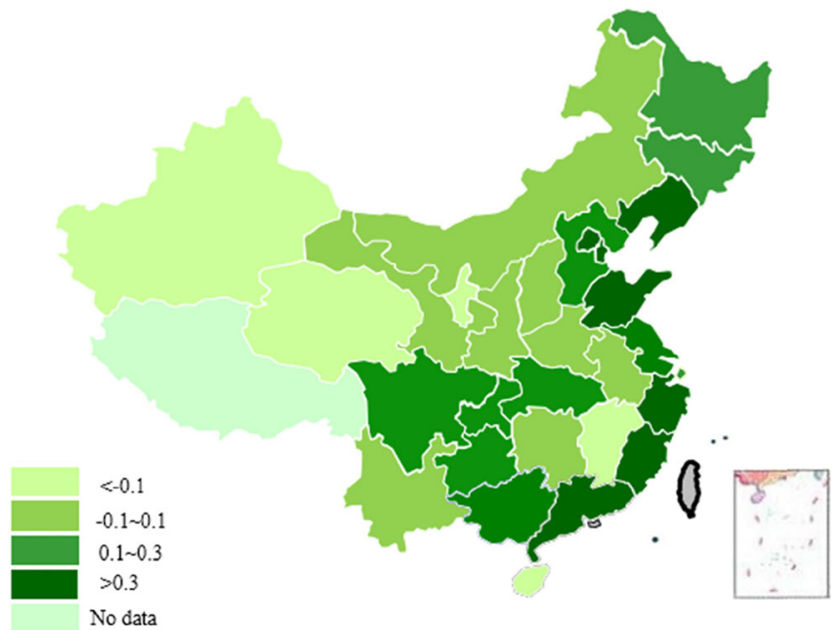

Fig. 7 Province fixed effect. It is a schematic map and does not implicate the definite boundaries

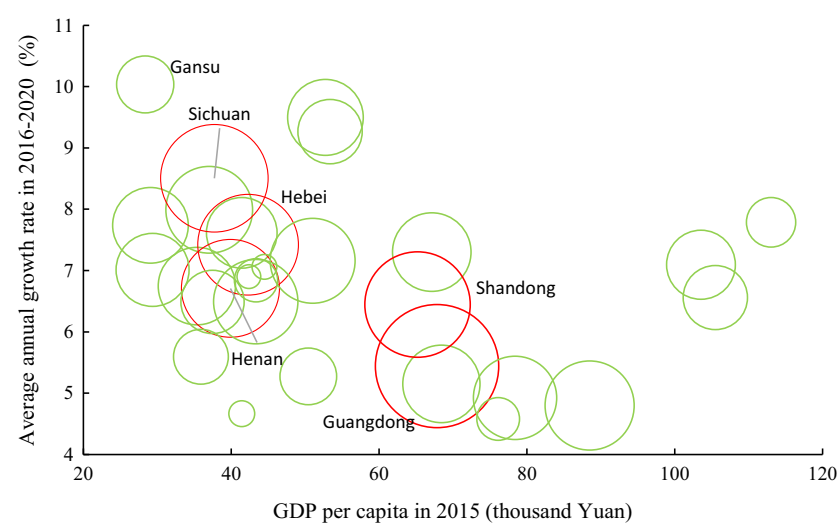

Fig. 8 Provincial average annual growth rate and increment in 20162020. Note: The size of bubble represents the increment in 2016-2020. Guangdong, Sichuan, Shandong, Hebei, and Henan rank the top 5 among all the provinces in terms of increment, which are highlighted as red bubbles

progress) are included in the fixed effects. Third, China has a fairly high rate of electrification in both urban and rural areas compared with other countries and achieved universal electricity access in 2015 . Therefore, the electricity access rate could be left uncontrolled. Fourth, it is easy to obtain authoritative or official projections of income, but it is difficult to obtain projections for regressors like urbanization rate and heating degree days. Besides, it is also the spirit of a reduced-form model with lower data requirements to use limited variables (Auffhammer and Steinhauser 2012).

\section{Data}

A panel of provincial data set is used to estimate and forecast. The panel data consist of 30 Chinese provinces, municipalities, and autonomous regions in mainland China, except for Tibet (because of a lack of data) in 1995-2014 period. We choose GDP as the measurement of income, and deflating the nominal GDP to real GDP using the province specific deflators with 2014 as the base year. To eliminate the influence

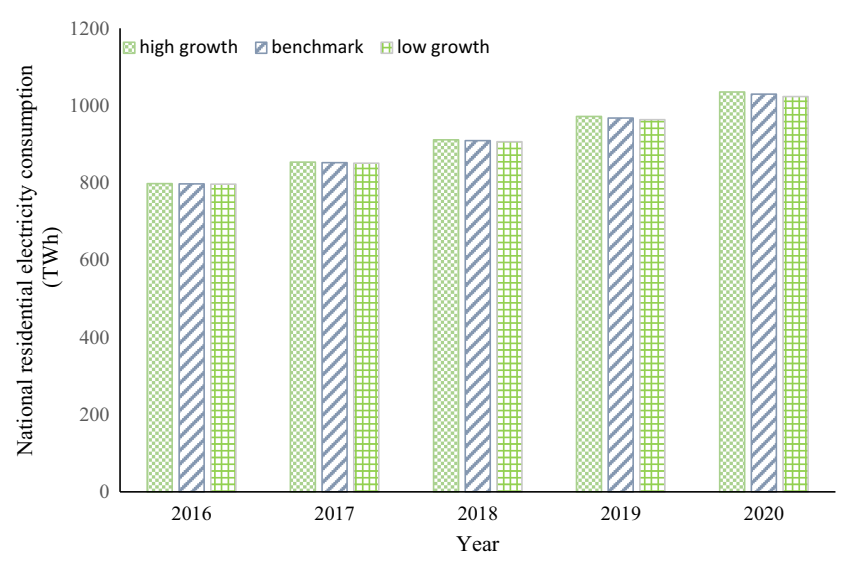

Fig. 9 Forecasts of national residential electricity consumption in 13th Five-Year-Plan period 
of population size, we divide the total residential electricity consumption and income by the total provincial population at year end. The provincial GDP and population data are obtained from the China Statistical Yearbook (1996-2015) published by the National Bureau of Statistics, and the residential electricity consumption data are extracted from the energy balance sheets by province in China Energy Statistical Yearbook (1996-2015). Chongqing was separated from Sichuan in 1997, so data from 1995 to 1996 are unavailable. The data set is unbalanced with 598 observations. The unit of measurement of per capita residential electricity consumption is kilowatt hour, and per capita income is measured in RMB Yuan. The descriptive statistics of the variables are summarized in Table 1.

\section{Estimation results}

To estimate piecewise linear model, the foremost step is to figure out where the meaningful breakpoints are. We divide the income range into 4-, 8-, and 10-segment splines by percentile, which means that each segment includes same number of observations. Small differences were detected in the estimate results of the three specifications. We only report the results of 4-segment on the ground of simplicity. The natural logarithms of the three GDP breakpoints are 9.20, 9.78, and 10.39 , respectively. Correspondingly, the original breakpoints of GDP are 9876, 17,625, and 32,378 Yuan.

Introducing lagged variable into fixed-effect model would lead to biased estimate coefficient because of the correlation between stochastic error term and the lagged dependent variable (Nickell 1981). System GMM developed by Arellano and Bond would produce consistent estimated coefficient (Arellano and Bond 1991; Conley 1999). Hence, we employ the system GMM to estimate and report the result in Table 2. The coefficient of lagged dependent variable is 0.7 , indicating the inertia of previous electricity consumption.

A visual display of income effect is shown in Fig. 3. The result indicates that each segment of income elasticity is positive but it decreases as the income increases. Specifically, the coefficient of last segment has fallen to 0.02 from 0.19 at the first segment. This suggests that $1 \%$ increase in income would bring in negligible increase in residential electricity consumption when the per capita income reaches at about 30,000 Yuan. Unlike fixed-specification model, piecewise linear model is not able to show the path of income effect out of sample. We make an assumption that the path of last segment will continue in the short run (2015-2020).

The decline of income elasticity manifests that income effect on residential electricity consumption is decreasing. It can partly be explained by the rapid growth of appliance ownership in China, as shown in Fig. 4. More and more appliances have been introduced into household during the past two decades. Particularly, appliance ownership has reached a very high level in urban area. By 2012, ownership of colored TVs in urban households had risen to $136 \%$, which means that each household has more than one television set on average. It reached $98 \%$ for washing machine, $98 \%$ for refrigerators, and $126 \%$ for air conditioners, respectively. Consequently, fewer and fewer appliances are purchased despite rising incomes. Hence, the residential electricity consumption driven by the ownership of appliance keeps stable or decline, leading to decreasing income elasticity.

\section{Forecasting technique and results}

\section{Assumptions of explanatory variables out of sample}

Before the forecasting, three important issues should be addressed in advance. First, we need to make an assumption of the explanatory variable of per capita income, i.e., both GDP and population by province are required to be assumed. Second, the time fixed effect, whose future value is unknown, is also required to be estimated.

There are many forecasts of China's GDP growth rate (e.g., World Bank, IMF, IHS, The Economist, etc.). However, they are only available at a national level. Here, we use the GDP growth target set by provincial governments in their 13th Five-Year Plan. Since 2015, China's economy has stepped into a "new normal," shifting from high-speed growth to medium-high growth. Chinese government has set a GDP growth target of $6.5 \%$ per year in 13th Five-Year-Plan period (2016-2020). In order to achieve the national goal, provincial and municipal government outlined their economic development goals individually for the next 5 years in accordance with their present status. We make an assumption that income will increase at the growth rate of provincial goals for GDP. Considering the uncertainties in economic development, we raise the goal by two percentage points as the high growth scenario and reduce the goal by two percentage points as the low growth scenario. The predicted GDP growth rates of 30 provinces in 2016-2020 under three different scenarios are listed in Appendix 1. Besides, since our sample data is available up to 2014, provincial GDP growth rates of 2015 are in need. Luckily, at the beginning of year 2016, the provincial and municipal government released 2015 GDP growth rate in their statistical bulletin, which are also listed in Appendix 1.

Provincial population projections are not available in China as well. When we take a careful look at the population growth rate of all provinces, little variation is found during the period 2010-2014. So we calculate the average population growth rate of the years 2010-2014 for each province and utilize them to assume future population to the year 2020, as shown in the last column of Appendix 1. We notice that China's government has deregulated the "one-child" policy to "two children". 
In our paper, we just predict the short run (5 years) electricity consumption; therefore, the recent two-child policy has little impacts on the electricity consumption in the near next 5 years. In addition, according to some influential reports such as Zeng and Hesketh (2016), universal two-child policy is predicted to have a relatively small effect on population and economic growth. We understand the increasing uncertainty due to the two-child policy in China; however, the population scenario is a large research project which is not suitable to discuss intensively in this paper.

The inclusion of time fixed effect in model poses a challenge to forecast them out of sample, because we have no knowledge of the year fixed effect in future periods. HoltzEakin and Selden (1995) made an assumption that the future time fixed effect equals to the last in-sample year, while Schmalensee et al. (1998) replaced the time fixed effect by time trend and forecasted them out of sample. Figure 5 presents a linear trend of time fixed effect in model (2), so we continue the linear trends into the out-of-sample periods following Schmalensee et al. (1998). The model form changed into the following one, and the estimated results are displayed in Table 2.

$$
\begin{aligned}
\ln E_{\mathrm{it}}= & \alpha_{0}+\alpha_{\mathrm{i}}+\text { Year }+\rho \ln \left(E_{\mathrm{it}-1}\right)+\beta_{\mathrm{k}} f\left[\ln \left(Y_{\mathrm{it}}\right)\right] \\
& +\varepsilon_{\mathrm{it}}
\end{aligned}
$$

\section{Forecast results}

\section{The provincial residential electricity consumption in 2016-2020}

By using model (2) and the estimated coefficients in Table 2, we construct out of sample forecast of provincial residential electricity consumption under three different scenarios and list the forecast results in Appendix 2. According to the forecast results, the residential electricity consumption of all provinces will increase with income rising in the 13th Five-Year-Plan period (2016-2020). But there are also some remarkable differences among provinces both at the per capita level and gross level which are summarized in the following. For simplicity, our discussion is based on the benchmark scenario.

(1) The provincial per capita residential electricity consumption

Firstly, large gap still can be seen clearly among different provinces in terms of per capita consumption level, as shown in Fig. 6. The residential electricity consumption per capita in highly developed provinces, such as Beijing, Shanghai,
Zhejiang, Fujian, and Guangdong, will boost up to $1000 \mathrm{kWh}$ in 2020. By contrast, in less-developed provinces, such as Ningxia, Jiangxi, Gansu, and Xinjiang, the number will be only about $500 \mathrm{kWh}$. There are possibly two main causes to the large gap. On the one hand, as suggested in the "Estimation results" section, the consumption of previous year has a significant influence on the current year. Consequently, provinces with higher level of residential electricity consumption in the past years also tend to be provinces with higher level of residential electricity consumption in the 13th FiveYear-Plan period (2016-2020). On the other hand, it can be explained by the province fixed effect, which captures the unobserved province heterogeneity such as geographical location and climatic conditions. As shown in Fig. 7, the estimated province fixed effect distributes in rundle at a rough glance: the east is the highest, followed by the middle, and the west is the lowest. Shanghai, Fujian, Guangdong, and Zhejiang rank the top 5, as they all lie in the southeast coastal area, where climate is characterized by hot, humid summers and cold, and humid winters. Cold or hot days mean that more electricity will be generally used for heating and cooling (Yang and Yu 2004). Futuremore, due to historical reasons, the residential buildings in the south region have no central heating systems. Therefore, a large amount of electricity demands for heating.

Secondly, different provinces show diverse growth rate in 2015-2020 compared with the previous years. Some developed provinces with high income per capita (e.g., Zhejiang, Fujian, and Guangdong) present a lower growth rate in 20152020 compared to that in previous years. While developing provinces with lower income per capita (e.g., Gansu, Ningxia, and Xinjiang) will keep the same or a higher growth rate in the 13th Five-Year-Plan period. This is mainly because the developed provinces will pass the end of income effect path in the next few years, where the income elasticity is quite small. But the income effect will be still relatively high for developing provinces due to their low income level in the next few years.

In addition, 95\% confidence intervals are calculated and marked to indicate the prediction reliability intuitively. But we should note that there is a disparity in terms of the size of confidence intervals. Less-developed provinces have short confidence intervals, which indicate the predictions are precise. However, developed provinces have much wider ones, which indicate these predictions are uncertain. As mentioned previously, the income elasticity of the last segment was employed to forecast when the income level is out of sample. For the highly developed provinces (Beijing, Shanghai, Tianjin), people will enjoy a higher level of income in 2016-2020 that has been beyond the last segment of sample. Therefore, we have less confidence about the developed province's forecast results. But the projection of less-developed province in the 2016-2020 is still in sample, so the forecast is more accurate. 
(2) The provincial gross residential electricity consumption

Taking population into consideration, the forecasting result of provincial gross residential electricity consumption is obtained. Figure 8 displays the provincial average annual growth rate and increment in 2016-2020 under the benchmark scenario. Similar to the forecast results of per capita amount, provinces with high income show low growth rate, while provinces with low income present accelerating rate. For example, less-developed province Gansu ranks the first with a rapid average annual growth rate of $10 \%$, which is twice as much as that of the highly developed province Zhejiang. From the perspective of increment, Guangdong, Sichuan, Shandong, Hebei, and Henan rank the top 5 among all the provinces, but it is easy to note that those provinces are populous.

\section{The national residential electricity consumption} in 2016-2020

We aggregate residential electricity consumption across provinces to get national residential electricity consumption in 2016-2020 and calculate the per capita amount by dividing the projected population in the corresponding years. As shown in Fig. 9, there is little disparity among high growth scenario, benchmark scenario, and low growth scenario. Under the benchmark scenario, the national electricity consumption will increase to 797 TWh in 2016 and 1029 TWh in 2020 by an average growth rate of $6.6 \%$ annually, and the per capita amount will be $580 \mathrm{kWh}$ in 2016 and $734 \mathrm{kWh}$ in 2020 . There will be $232 \mathrm{TWh}$ increments during the 13th FiveYear-Plan period. As displayed in Fig. 8, populous provinces (Guangdong, Henan, Hebei, Sichuan, and Shandong) will be the main contributors.

\section{Conclusions and policy implications}

An accurate electricity demand forecast in resident sector is a prerequisite for the fast-growing developing countries, as it can reduce the possibility of errors during electricity system planning and energy policy designing. In this paper, we forecast the provincial and national residential electricity demand of China in the 13th Five-Year-Plan period (2016-2020) using province-level panel data over 1995-2014. A piecewise linear model in reduced form is utilized that can capture the nondeterministic relationship between income and residential electricity consumption with low data requirement. Based on the estimations and forecast results, several conclusions and policy implications are as follows.

First of all, the income effect on residential electricity consumption has decreased in the past two decades. Specifically, the coefficient of the last segment has fallen to 0.02 from 0.19 at the first segment. This suggests that the income effect becomes negligible when per capita income reaches at about 30,000 Yuan. In addition, the coefficient of lagged dependent variable is 0.7 , indicating the significant impact of previous electricity consuming habit. This tells us the household energy consumption pattern is sticky in China and it is better for policy makers to help the residents shape good electricity using habits (Yin et al. 2016).

Secondly, the residential electricity consumption of all provinces will increase during the 13th Five-Year-Plan period (2016-2020). The growth rates of highly developed provinces, such as Zhejiang, Fujian, and Guangdong, show signs of slowing. By contrast, residents in less-developed provinces, such as Ningxia, Jiangxi, Gansu, and Xinjiang, show accelerating growth rate.

Thirdly, there is little disparity among high growth scenario, benchmark scenario, and low growth scenario. Under the benchmark scenario, the national electricity demand will increase to 797 TWh in 2016 and 1029 TWh in 2020 with an average annual growth rate of $6.6 \%$. There will be $232 \mathrm{TWh}$ increments during the 13th Five-Year-Plan period and populous provinces (Guangdong, Henan, Hebei, Sichuan, and Shandong) will be the main contributors.

To sum up, the Chinese electricity consumption in resident sector will still be on the track of increase during the 13th Five-Year-Plan period (2016-2020), but the increment and growth rate are different among different regions. In response to meeting the increasing demand in all regions, energy policy formulating and electricity system planning should be in line with the local conditions specifically. For example, grid modification and upgrading project should speed up in western and rural areas, where the power grid structures are relatively weak, addressing the problems like substandard voltage and insufficient power supply. By building a well-functioning electric power system, resident can enjoy reliable electricity service. Besides, as the main contributors to the increment, populous provinces (Guangdong, Henan, Hebei, Sichuan, and Shandong) deserve more attention, but it is worth mentioning that there is no moral ground to constrain residents' electricity consumption to combat the global warming (Yin et al. 2016). Introducing higher efficiency standards for electrical appliances and guiding residents to conserve electricity and reduce electricity waste are of vital importance.

Acknowledgements We thank the financial supports from the China's National Key R\&D Program (2016YFA0602603, 2016YFA0602801) and National Natural Science Foundation of China (No. 71322306, $71273027,71521002,71673026)$. We are grateful to the anonymous referees for comments and constructive suggestions that have considerably improved the quality of this paper. The views expressed in this paper are solely authors' own and do not necessarily reflect the views of the supporting agencies and authors' affiliations. The authors alone are responsible for any remaining deficiencies. 


\section{Appendix 1}

Table 3 The projected GDP growth rate and population growth rate in 2015-2020

\begin{tabular}{|c|c|c|c|c|c|c|c|}
\hline \multirow[t]{3}{*}{ Province } & \multicolumn{6}{|c|}{ GDP growth rate } & \multirow{3}{*}{$\begin{array}{l}\text { Population } \\
\text { growth rate }\end{array}$} \\
\hline & \multicolumn{2}{|c|}{ Low (\%) } & \multicolumn{2}{|c|}{ Benchmark (\%) } & \multicolumn{2}{|c|}{ High (\%) } & \\
\hline & 2015 & $\begin{array}{l}2016- \\
2020\end{array}$ & 2015 & $\begin{array}{l}2016- \\
2020\end{array}$ & 2015 & $\begin{array}{l}2016- \\
2020\end{array}$ & \\
\hline Beijing & 6.9 & 4.5 & 6.9 & 6.5 & 6.9 & 8.5 & 4.2 \\
\hline Tianjin & 9.3 & 7 & 9.3 & 9 & 9.3 & 11 & 2.4 \\
\hline Hebei & 6.8 & 5 & 6.8 & 7 & 6.8 & 9 & 6.6 \\
\hline Shanxi & 3.1 & 4 & 3.1 & 6 & 3.1 & 8 & 5.1 \\
\hline Inner Mongolia & 7.7 & 5.5 & 7.7 & 7.5 & 7.7 & 9.5 & 3.6 \\
\hline Liaoning & 3 & 4 & 3 & 6 & 3 & 8 & 0.1 \\
\hline Jilin & 6.5 & 5 & 6.5 & 7 & 6.5 & 9 & 0.8 \\
\hline Heilongjiang & 5.7 & 4.5 & 5.7 & 6.5 & 5.7 & 8.5 & 1.3 \\
\hline Shanghai & 6.9 & 5 & 6.9 & 7 & 6.9 & 9 & 2.8 \\
\hline Jiangsu & 8.5 & 6 & 8.5 & 8 & 8.5 & 10 & 2.6 \\
\hline Zhejiang & 8 & 5.5 & 8 & 7.5 & 8 & 9.5 & 4.6 \\
\hline Anhui & 8.7 & 6.5 & 8.7 & 8.5 & 8.7 & 10.5 & 6.7 \\
\hline Fujian & 9 & 6.5 & 9 & 8.5 & 9 & 10.5 & 6.6 \\
\hline Jiangxi & 9.1 & 6.5 & 9.1 & 8.5 & 9.1 & 10.5 & 7.3 \\
\hline Shandong & 8 & 6 & 8 & 8 & 8 & 10 & 5.6 \\
\hline Henan & 8.3 & 6 & 8.3 & 8 & 8.3 & 10 & 5.3 \\
\hline Hubei & 8.9 & 7 & 8.9 & 9 & 8.9 & 11 & 4.7 \\
\hline Hunan & 8.6 & 6.5 & 8.6 & 8.5 & 8.6 & 10.5 & 6.5 \\
\hline Guangdong & 8 & 5.5 & 8 & 7.5 & 8 & 9.5 & 6.4 \\
\hline Guangxi & 8.1 & 6 & 8.1 & 8 & 8.1 & 10 & 8 \\
\hline Hainan & 7.8 & 5.5 & 7.8 & 7.5 & 7.8 & 9.5 & 8.8 \\
\hline Chongqing & 11 & 8 & 11 & 10 & 11 & 12 & 3.4 \\
\hline Sichuan & 7.9 & 5 & 7.9 & 7 & 7.9 & 9 & 2.9 \\
\hline Guizhou & 10.7 & 8 & 10.7 & 10 & 10.7 & 12 & 6.4 \\
\hline Yunnan & 8.7 & 6.5 & 8.7 & 8.5 & 8.7 & 10.5 & 6.3 \\
\hline Shaanxi & 8 & 6 & 8 & 8 & 8 & 10 & 3.8 \\
\hline Gansu & 8.1 & 5.5 & 8.1 & 7.5 & 8.1 & 10.5 & 6.1 \\
\hline Qinghai & 8.2 & 5.5 & 8.2 & 7.5 & 8.2 & 9.5 & 8.3 \\
\hline Ningxia & 8 & 5.5 & 8 & 7.5 & 8 & 9.5 & 8.8 \\
\hline Xinjiang & 8.6 & 5 & 8.6 & 7 & 8.6 & 9 & 10.9 \\
\hline
\end{tabular}

The projected GDP growth rates under benchmark scenario in 2016-2020 are extracted from provincial and municipal 13th Five-Year Plan. Based on the benchmark scenario, we raise the rate by two percentage points as the high growth scenario and reduce the rate by two percentage points as the low growth scenario. GDP growth rates in 2015 are obtained from the provincial economy and society-developed statistical bulletin. Population growth rates are the average of 2010-2014 
Appendix 2: Forecast results of residential electricity consumption in the 13th Five-Year Plan

Table 4 Forecast residential electricity consumption in the 13th FiveYear Plan under benchmark scenario

\begin{tabular}{|c|c|c|c|c|c|}
\hline Year & 2016 & 2017 & 2018 & 2019 & 2020 \\
\hline Anhui & 287.40 & 313.09 & 338.69 & 364.53 & 390.91 \\
\hline Beijing & 196.60 & 210.32 & 224.28 & 238.63 & 253.48 \\
\hline Chongqing & 180.32 & 200.78 & 220.57 & 239.96 & 259.22 \\
\hline Fujian & 370.10 & 387.12 & 406.65 & 428.47 & 452.45 \\
\hline Gansu & 95.99 & 107.69 & 118.95 & 129.90 & 140.72 \\
\hline Guangdong & 885.04 & 930.23 & 980.24 & 1034.85 & 1093.97 \\
\hline Guangxi & 275.37 & 294.62 & 314.64 & 335.57 & 357.54 \\
\hline Guizhou & 226.94 & 246.19 & 265.59 & 285.39 & 305.77 \\
\hline Hainan & 45.90 & 47.65 & 49.79 & 52.28 & 55.08 \\
\hline Hebei & 421.35 & 455.70 & 490.17 & 525.16 & 561.05 \\
\hline Heilongjiang & 201.58 & 219.21 & 236.39 & 253.35 & 270.35 \\
\hline Henan & 444.34 & 475.76 & 508.01 & 541.38 & 576.13 \\
\hline Hubei & 310.37 & 334.37 & 358.69 & 383.57 & 409.27 \\
\hline Hunan & 342.06 & 364.79 & 388.59 & 413.58 & 439.92 \\
\hline Inner Mongolia & 127.22 & 132.23 & 138.12 & 144.79 & 152.18 \\
\hline Jiangsu & 530.61 & 553.38 & 579.39 & 608.34 & 640.04 \\
\hline Jiangxi & 192.86 & 205.59 & 218.97 & 233.08 & 247.99 \\
\hline Jilin & 134.65 & 149.86 & 164.34 & 178.29 & 191.93 \\
\hline Liaoning & 260.87 & 282.65 & 303.86 & 324.81 & 345.78 \\
\hline Ningxia & 26.98 & 28.99 & 31.06 & 33.21 & 35.45 \\
\hline Qinghai & 25.30 & 27.13 & 29.02 & 30.99 & 33.04 \\
\hline Shaanxi & 193.37 & 202.95 & 213.52 & 225.05 & 237.50 \\
\hline Shandong & 538.74 & 574.58 & 611.85 & 650.81 & 691.68 \\
\hline Shanghai & 207.60 & 223.88 & 240.09 & 256.44 & 273.10 \\
\hline Shanxi & 169.90 & 179.23 & 189.21 & 199.87 & 211.22 \\
\hline Sichuan & 413.21 & 454.58 & 494.56 & 533.76 & 572.74 \\
\hline Tianjin & 95.82 & 104.27 & 112.59 & 120.92 & 129.34 \\
\hline Xinjiang & 84.44 & 90.40 & 96.62 & 103.15 & 110.03 \\
\hline Yunnan & 234.95 & 252.45 & 270.37 & 288.86 & 308.09 \\
\hline Zhejiang & 450.70 & 470.56 & 493.25 & 518.52 & 546.22 \\
\hline Sum & 7970.59 & 8520.25 & 9088.06 & 9677.51 & $10,292.19$ \\
\hline
\end{tabular}

Table 5 Forecast residential electricity consumption in the 13th FiveYear Plan under high growth scenario

\begin{tabular}{|c|c|c|c|c|c|}
\hline Year & 2016 & 2017 & 2018 & 2019 & 2020 \\
\hline Anhui & 287.56 & 313.56 & 339.62 & 366.06 & 393.17 \\
\hline Beijing & 196.71 & 210.64 & 224.91 & 239.65 & 254.97 \\
\hline Chongqing & 180.42 & 201.08 & 221.17 & 240.95 & 260.70 \\
\hline Fujian & 370.30 & 387.71 & 407.76 & 430.26 & 455.07 \\
\hline Gansu & 96.33 & 108.15 & 119.61 & 130.86 & 142.05 \\
\hline Guangdong & 885.53 & 931.64 & 982.95 & 1039.23 & 1100.37 \\
\hline Guangxi & 275.52 & 295.06 & 315.50 & 336.98 & 359.63 \\
\hline Guizhou & 227.46 & 246.87 & 266.56 & 286.76 & 307.67 \\
\hline Hainan & 45.92 & 47.72 & 49.93 & 52.50 & 55.40 \\
\hline Hebei & 421.58 & 456.40 & 491.53 & 527.40 & 564.35 \\
\hline Heilongjiang & 201.70 & 219.55 & 237.05 & 254.44 & 271.94 \\
\hline Henan & 444.59 & 476.47 & 509.41 & 543.66 & 579.48 \\
\hline Hubei & 310.54 & 334.87 & 359.66 & 385.17 & 411.63 \\
\hline Hunan & 342.25 & 365.34 & 389.65 & 415.32 & 442.47 \\
\hline Inner Mongolia & 127.29 & 132.43 & 138.50 & 145.40 & 153.07 \\
\hline Jiangsu & 530.91 & 554.22 & 580.99 & 610.91 & 643.77 \\
\hline Jiangxi & 192.96 & 205.90 & 219.57 & 234.06 & 249.42 \\
\hline Jilin & 134.73 & 150.09 & 164.80 & 179.05 & 193.06 \\
\hline Liaoning & 261.01 & 283.08 & 304.71 & 326.20 & 347.84 \\
\hline Ningxia & 27.00 & 29.04 & 31.15 & 33.35 & 35.66 \\
\hline Qinghai & 25.32 & 27.17 & 29.10 & 31.12 & 33.24 \\
\hline Shaanxi & 193.48 & 203.25 & 214.11 & 226.00 & 238.89 \\
\hline Shandong & 539.03 & 575.45 & 613.54 & 653.55 & 695.71 \\
\hline Shanghai & 207.72 & 224.22 & 240.76 & 257.53 & 274.70 \\
\hline Shanxi & 170.00 & 179.50 & 189.74 & 200.73 & 212.47 \\
\hline Sichuan & 413.44 & 455.27 & 495.94 & 536.03 & 576.11 \\
\hline Tianjin & 95.88 & 104.42 & 112.90 & 121.42 & 130.09 \\
\hline Xinjiang & 84.49 & 90.53 & 96.89 & 103.59 & 110.68 \\
\hline Yunnan & 235.50 & 253.16 & 271.36 & 290.27 & 310.03 \\
\hline Zhejiang & 450.95 & 471.27 & 494.62 & 520.72 & 549.41 \\
\hline Sum & 7976.12 & 8534.07 & 9113.97 & 9719.13 & $10,353.04$ \\
\hline
\end{tabular}


Table 6 Forecast residential electricity consumption in the 13th FiveYear Plan under low growth scenario

\begin{tabular}{|c|c|c|c|c|c|}
\hline Year & 2016 & 2017 & 2018 & 2019 & 2020 \\
\hline Anhui & 287.24 & 312.61 & 337.75 & 362.98 & 388.61 \\
\hline Beijing & 196.48 & 209.99 & 223.65 & 237.60 & 251.96 \\
\hline Chongqing & 180.22 & 200.48 & 219.96 & 238.95 & 257.72 \\
\hline Fujian & 369.89 & 386.53 & 405.52 & 426.64 & 449.79 \\
\hline Gansu & 95.76 & 106.99 & 118.18 & 129.01 & 139.62 \\
\hline Guangdong & 884.54 & 928.79 & 977.48 & 1030.41 & 1087.49 \\
\hline Guangxi & 275.22 & 294.17 & 313.76 & 334.13 & 355.44 \\
\hline Guizhou & 226.41 & 245.50 & 264.62 & 284.00 & 303.85 \\
\hline Hainan & 45.87 & 47.57 & 49.65 & 52.05 & 54.75 \\
\hline Hebei & 421.11 & 455.00 & 488.78 & 522.90 & 557.71 \\
\hline Heilongjiang & 201.47 & 218.87 & 235.72 & 252.26 & 268.73 \\
\hline Henan & 444.09 & 475.03 & 506.58 & 539.07 & 572.73 \\
\hline Hubei & 310.20 & 333.86 & 357.69 & 381.95 & 406.88 \\
\hline Hunan & 341.87 & 364.24 & 387.50 & 411.83 & 437.34 \\
\hline Inner Mongolia & 127.15 & 132.02 & 137.73 & 144.17 & 151.27 \\
\hline Jiangsu & 530.31 & 552.53 & 577.77 & 605.74 & 636.27 \\
\hline Jiangxi & 192.75 & 205.28 & 218.36 & 232.09 & 246.53 \\
\hline Jilin & 134.57 & 149.63 & 163.87 & 177.52 & 190.79 \\
\hline Liaoning & 260.72 & 282.21 & 302.99 & 323.39 & 343.71 \\
\hline Ningxia & 26.97 & 28.95 & 30.98 & 33.07 & 35.24 \\
\hline Qinghai & 25.29 & 27.09 & 28.94 & 30.86 & 32.85 \\
\hline Shaanxi & 193.26 & 202.63 & 212.92 & 224.09 & 236.10 \\
\hline Shandong & 538.43 & 573.70 & 610.14 & 648.03 & 687.60 \\
\hline Shanghai & 207.48 & 223.53 & 239.41 & 255.33 & 271.47 \\
\hline Shanxi & 169.81 & 178.95 & 188.67 & 199.00 & 209.95 \\
\hline Sichuan & 412.98 & 453.87 & 493.16 & 531.46 & 569.34 \\
\hline Tianjin & 95.77 & 104.11 & 112.28 & 120.40 & 128.58 \\
\hline Xinjiang & 84.40 & 90.26 & 96.34 & 102.70 & 109.38 \\
\hline Yunnan & 234.39 & 251.74 & 269.36 & 287.44 & 306.13 \\
\hline Zhejiang & 450.44 & 469.83 & 491.86 & 516.30 & 542.98 \\
\hline Sum & 7965.07 & 8505.96 & 9061.65 & 9635.35 & $10,230.82$ \\
\hline
\end{tabular}

\section{References}

Adams FG, Shachmurove Y (2008) Modeling and forecasting energy consumption in China: implications for Chinese energy demand and imports in 2020. Energy Econ 30:1263-1278

Alberini A, Gans W, Velez-Lopez D (2011) Residential consumption of gas and electricity in the U.S.: the role of prices and income. Energy Econ 33:870-881

Arellano M, Bond S (1991) Some tests of specification for panel data: Monte Carlo evidence and an application to employment equations. Review of Economic Studies 58:277-297

Auffhammer M, Carson RT (2008) Forecasting the path of China's $\mathrm{CO} 2$ emissions using provincelevel information. Journal of Environmental Economics and Management 55: 229-247

Auffhammer M, Steinhauser R (2012) Forecasting the path of US CO2 emissions using state-level information. Review of Economics and Statistics 94:172-185
Blázquez L, Boogen N, Filippini M (2013) Residential electricity demand in Spain: new empirical evidence using aggregate data. Energy Econ 36:648-657

Conley TG (1999) GMM estimation with cross sectional dependence. J Econ 92:1-45

Darbellay GA, Slama M (2000) Forecasting the short-term demand for electricity: do neural networks stand a better chance? Int J Forecast 16:71-83

Dergiades T, Tsoulfidis L (2008) Estimating residential demand for electricity in the United States, 1965-2006. Energy Econ 30:2722-2730

Dikaios Tserkezos E (1992) Forecasting residential electricity consumption in Greece using monthly and quarterly data. Energy Econ 14: 226-232

Holtedahl P, Joutz FL (2004) Residential electricity demand in Taiwan. Energy Econ 26:201-224

Hondroyiannis G (2004) Estimating residential demand for electricity in Greece. Energy Econ 26:319-334

Liao H, Cai JW, Yang DW, Wei YM (2016) Why did the historical energy forecasting succeed or fail? A case study on IEA's projection. Technol Forecast Soc Chang 107:90-96

Liao H, Cao HS (2013) How does carbon dioxide emission change with the economic development? Statistical experiences from 132 countries. Glob Environ Chang 23:1073-1082

Lin BQ (2003) Electricity demand in the People's Republic of China: investment requirement and environmental impact. Asian Development Bank, Manila

Mohamed Z, Bodger P (2005) A comparison of logistic and Harvey models for electricity consumption in New Zealand. Technol Forecast Soc Chang 72:1030-1043

Musango JK (2014) Household electricity access and consumption behaviour in an urban environment: the case of Gauteng in South Africa. Energy Sust Dev 23:305-316

Nickell S (1981) Biases in dynamic models with fixed effects. Econometrica: J Econometric Soc:1417-1426

Pappas SS, Ekonomou L, Karamousantas DC, Chatzarakis GE, Katsikas SK, Liatsis P (2008) Electricity demand loads modeling using auto regressive moving average (ARMA) models. Energy 33:1353-1360

Sadeghi Keyno HR, Ghaderi F, Azade A, Razmi J (2009) Forecasting electricity consumption by clustering data in order to decline the periodic variable's affects and simplification the pattern. Energy Convers Manag 50:829-836

Schmalensee R, Stoker TM, Judson RA (1998) World carbon dioxide emissions: 1950-2050. Review of Economics and Statistics $80: 15-27$

Schweizer VJ, Morgan MG (2016) Bounding US electricity demand in 2050. Technol Forecast Soc Chang 105:215-223

Steenhof PA, Fulton W (2007) Factors affecting electricity generation in China: current situation and prospects. Technol Forecast Soc Chang 74:663-681

Son H, Kim C (2016) Short-term forecasting of electricity demand for the residential sector using weather and social variables. Resour Conserv Recycl. doi:10.1016/j.resconrec.2016.01.016

von Hirschhausen C, Andres M (2000) Long-term electricity demand in China-from quantitative to qualitative growth? Energy Policy 28: 231-241

Yang M, Yu X (2004) China's rural electricity market - a quantitative analysis. Energy 29:961-977

Yin H, Zhou H, Zhu K (2016) Long- and short-run elasticities of residential electricity consumption in China: a partial adjustment model with panel data. Appl Econ 48:2587-2599

Yoo SH, Lee JS (2010) Electricity consumption and economic growth: a cross-country analysis. Energy Policy 38:622-625

Zeng Y, Hesketh T (2016) The effects of China's universal two-child policy. Lancet 388:1930-1938 